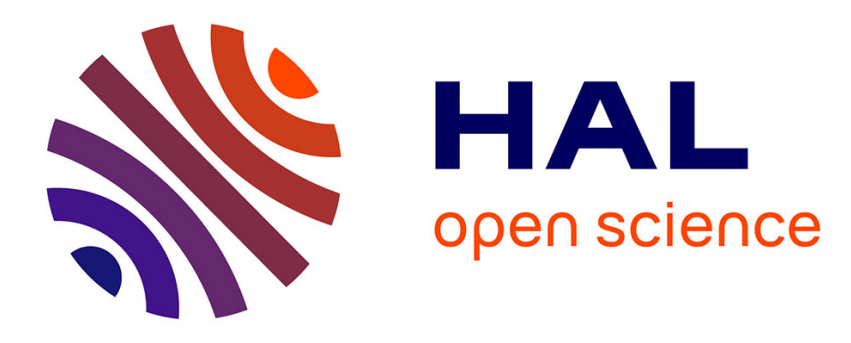

\title{
On characteristic parameters involved in dynamic fragmentation processes
}

François Hild

\section{To cite this version:}

François Hild. On characteristic parameters involved in dynamic fragmentation processes. Mechanics of Materials, 2015, 80B, pp.340-350. 10.1016/j.mechmat.2013.11.012 . hal-01167018

\section{HAL Id: hal-01167018 \\ https://hal.science/hal-01167018}

Submitted on 23 Jun 2015

HAL is a multi-disciplinary open access archive for the deposit and dissemination of scientific research documents, whether they are published or not. The documents may come from teaching and research institutions in France or abroad, or from public or private research centers.
L'archive ouverte pluridisciplinaire HAL, est destinée au dépôt et à la diffusion de documents scientifiques de niveau recherche, publiés ou non, émanant des établissements d'enseignement et de recherche français ou étrangers, des laboratoires publics ou privés. 


\title{
On Characteristic Parameters Involved in Dynamic Fragmentation Processes
}

\author{
François Hild \\ Laboratoire de Mécanique et Technologie (LMT-Cachan) \\ ENS Cachan / CNRS / UPMC / PRES UniverSud Paris \\ 61 Avenue du Président Wilson, F-94235 Cachan Cedex, France
}

\begin{abstract}
Dynamic loadings produce high stress waves leading to the fragmentation of brittle materials such as ceramics, concrete, glass, and rocks, or ductile materials such as steels and alloys. The main mechanism used herein to explain the change of the number of fragments with strain and stress rates is an obscuration (or shielding) phenomenon associated with cracking or cavitation. A probabilistic framework, which is based upon a Poisson point process, is introduced. Nonlocal (in space and time) expressions are obtained to account for multiple crack initiations or void nucleations, and their subsequent growth. This approach allows characteristic parameters (i.e. size, stress, stress rate, and time) involved in the fragmentation processes to be introduced. Examples are discussed to illustrate the use of these characteristic parameters in the analysis of dynamic fragmentation of brittle materials and spallation of tantalum.
\end{abstract}

Email address: hild@lmt.ens-cachan.fr (François Hild) 
Keywords: Damage, obscuration, Poisson point process, Weibull law

\section{Introduction}

Dynamic loadings induce very severe degradations in brittle and ductile materials. In brittle materials, very dense crack patterns are observed when impacted by projectiles or loaded by blast (e.g. see Rinehart, 1965; Kutter and Fairhurst, 1971; Shockey et al., 1974; Hornemann et al., 1984; Cagnoux, 1985; Strassburger et al., 1994). Similarly, ductile spallation is the result of nucleation and growth (and possibly coalescence) of many cavities in a given region associated with the interaction of stress waves (e.g. see Mott, 1947; Meyers and Aimone, 1983; Grady, 1988; Curran et al., 1993).

In many instances, the elementary damage mechanisms are studied (i.e. either a single propagating crack (e.g. see Freund, 1972; Ravi-Chandar and Knauss, 1982; Strassburger and Senf, 1995), or a single growing cavity (e.g. see Carroll and Holt, 1972; Glennie, 1972; Ortiz and Molinari, 1992; Molinari and Mercier, 2001)). Of the three phases of the fragmentation process, namely, initiation, propagation and coalescence of cracks, or nucleation, growth and coalescence of voids, the main emphasis is therefore put on the modeling of propagation and growth. The validation of the developed models is generally performed with comparisons to macroscopic data, which are very difficult to extract from dynamic experiments.

Probabilistic aspects associated with brittle or ductile fragmentations were recognized very early on (Mott, 1947; Shockey et al., 1974; Grady and 
Kipp, 1980). The Weibull law has been used as basis to describe inception mechanisms regimes (Denoual et al., 1997; Czarnota et al., 2006). However, their experimental characterization is even more difficult since it requires statistical data and possibly some information on their development during the test. The use of high speed imaging has allowed some progress to be made in the understanding of the experiment. However, in many instances, the pictures are used in a qualitative way. For brittle materials, the development of so-called edge-on-impact experiments has brought new insights into the cracking process of brittle materials (Strassburger et al., 1994; Riou et al., 1998). It is even possible to measure displacement fields (Bertin-Mourot et al., 1997) and then use the strain fields to validate damage models (Denoual and Hild, 2000, 2002).

One important aspect related to fragmentation studies is the interaction between growing cracks and voids and the inception of new voids (Mott, 1947) or cracks (Denoual et al., 1997). Some of the potential sites where inception may take place are inhibited because too close to growing cracks or voids. This phenomenon has been analyzed within the framework of Poisson point processes for brittle (Denoual et al., 1997; Grady, 2006) and ductile materials (Trumel et al., 2009). It will be used herein in a unified way to analyze dynamic fragmentation.

The aim of the present paper is to introduce characteristic parameters describing the fragmentation of brittle and ductile materials within the framework of continuum damage mechanics (Lemaitre, 1992). In Section 2 the 
Poisson-Weibull formalism is introduced to account for the inception and growth of cracks and pores. Governing equations are derived to estimate the activated and growing site densities. Characteristic parameters are then introduced in Section 3 for quasi-static and dynamic loading conditions. Various uses of the characteristic parameters are shown in Section 4.

\section{Probabilistic Framework}

The physical processes of inception and growth are complex under dynamic loading conditions. Wave propagation leads to nonuniform stress fields at the scale of the studied volume element. Due to the material microstructure additional fluctuations arise because of its heterogeneous nature. Inception will be described hereafter when the local stress $\sigma(\mathbf{x}, t)$ exceeds an inception threshold $\sigma_{i n c}(\mathbf{x})$. The stress $\sigma$ corresponds to the maximum principal stress $\sigma_{1}$ for brittle materials, and the hydrostatic stress $\sigma_{h}$ for ductile materials.

Once inception has occurred, an initiated crack or a nucleated void starts to grow. The growth process is accompanied by a relaxation zone in which the local stresses decrease (and are no longer equal to the levels that would have been reached had inception not occurred). Outside the relaxation zone the stress field is assumed to be unaltered by the presence of the growing cavity or propagating crack. In the context of continuum damage mechanics (Lemaitre, 1992), the relaxation zones define the damaged regions in which the material no longer sustains the applied stresses. 


\subsection{Description of Inception}

To account for such complex situations, a very simple probabilistic model is introduced. All the heterogeneities are lumped into a random inception stress when considering the macroscopic stress field (Trumel et al., 2009). The number $N$ of sites where the applied stress exceeds the inception threshold is assumed to follow a Poisson point process. The probability $P$ of finding $N=\nu$ sites in a uniformly loaded domain $\Omega$ reads

$$
P(N=\nu, \Omega)=\frac{\Lambda^{\nu}}{\nu !} \exp (-\Lambda),
$$

where $\Lambda$ is the average number of sites in $\Omega$. The intensity of the Poisson point process is defined by

$$
\lambda=\frac{\Lambda}{\mu_{n}(\Omega)},
$$

where $\mu_{n}$ is the Lebesgue measure in $\mathbb{R}^{n}$ (i.e. length of $\Omega$ when $n=1$, surface of $\Omega$ when $n=2$, and volume of $\Omega$ when $n=3$ ). The intensity $\lambda$ corresponds to the density of sites that may initiate a crack or nucleate a cavity. If the domain $\Omega$ is not uniformly loaded, the previous expression can be extended to

$$
\Lambda=\int_{\Omega} \lambda(\mathbf{x}) \mathrm{d} \mathbf{x} .
$$

In the following, it will be assumed that the intensity $\lambda$ of the inception process will depend on the applied stress level, namely, the higher the stress level, the higher the intensity as more sites will satisfy the inception condition (i.e. $\left.\sigma(\mathbf{x}, t) \geq \sigma_{i n c}(\mathbf{x})\right)$. 


\subsection{Inception Probability}

A first consequence of this type of modeling is related to the additional assumption of weakest link statistics (Pierce, 1926; Freudenthal, 1968). The inception probability corresponds to the first inception event. The probability $P_{i n c}$ of finding at least one inception site reads

$$
P_{\text {inc }}=P(N \geq 1, \Omega)=1-P(N=0, \Omega)=1-\exp (-\Lambda) .
$$

This type of hypothesis is known to accurately describe the behavior of brittle materials when subjected to quasi-static loading histories (Weibull, 1939, 1951). If a Weibull model is to be retrieved, it follows that

$$
\lambda=\lambda_{0}\left(\frac{\langle\sigma\rangle}{\sigma_{0}}\right)^{m}
$$

where $m$ is the shape parameter (or Weibull modulus), $\sigma_{0} / \lambda_{0}^{1 / m}$ the so-called scale parameter, $\sigma$ the local equivalent stress, and $\langle\cdot\rangle$ Macauley's brackets.

The mean stress at first inception $\bar{\sigma}_{i}$ is given by

$$
\bar{\sigma}_{i}=\frac{\sigma_{0}}{\left(\lambda_{0} \mu_{n}(\Omega) H_{m}\right)^{1 / m}} \Gamma\left(\frac{m+1}{m}\right)
$$

and the corresponding standard deviation $\overline{\bar{\sigma}}_{i}$

$$
\overline{\bar{\sigma}}_{i}=\frac{\sigma_{0}}{\left(\lambda_{0} V_{\mathrm{eff}}\right)^{1 / m}} \sqrt{\Gamma\left(\frac{m+2}{m}\right)-\Gamma^{2}\left(\frac{m+1}{m}\right)},
$$

where $\Gamma$ is the Euler (gamma) function of the second kind, and $H_{m}$ the stress heterogeneity factor (Hild et al., 1992)

$$
H_{m}=\frac{1}{\mu_{n}(\Omega)} \int_{\Omega}\left(\frac{\sigma}{\sigma_{m}}\right)^{m} \mathrm{~d} \mathbf{x} \text { with } \sigma_{m}=\max _{\Omega} \sigma(\mathbf{x}) .
$$


The product $\mu_{3}(\Omega) H_{m}$ corresponds to the so-called effective volume (Davies, 1973 ), and $\mu_{2}(\Omega) H_{m}$ the effective surface (Gy and Guillemet, 1992; Oakley, 1996).

The Weibull parameters used to model the intensity $\lambda$ of the Poisson point process are representative of the material microstructure, and more precisely the distribution of inception sites. The Weibull modulus mainly characterizes the scatter of the considered distribution since the coefficient of variation $\overline{\bar{\sigma}}_{i} / \bar{\sigma}_{i}$ only depends on $m$. Consequently, different Weibull moduli are an indication of different populations of inception sites, in particular for the lower stress levels, i.e. the ones likely to initiate failure under quasi-static loading conditions.

For a given reference density $\lambda_{0}$, different stress levels $\sigma_{0}$ are induced by different local toughnesses and defect sizes (for brittle materials) or yield stresses (for ductile materials). Different inception populations will therefore lead to different Weibull parameters. Conversely, different Weibull parameters are indicators of different distributions of inception stresses. When dealing with dynamic fragmentation, the Weibull model itself can no longer be used since the weakest link hypothesis does not apply. However, the following microstructure model (i.e. Poisson point process) still using Weibull parameters is considered. It has to be valid for describing single and multiple fragmentation regimes. Its advantage then lies in the fact that quasi-static experiments may be used to identify the material parameters (Denoual and Hild, 2000; Hild et al., 2003; Forquin and Hild, 2010). Once they are de- 
termined, they can be used in situations in which single fragmentation no longer occurs (e.g. dynamic fragmentation).

\subsection{Modeling of Growth}

When inception has occurred, the next question to address is growth. Dealing with waves, it is logical to relate the growth of cracks or cavities to the corresponding wave speeds. For cracks in an elastic medium, the longitudinal wave speed $c_{0}$ is a natural choice since it has been shown that the crack propagation velocity is a fraction of the former (Freund, 1972; RaviChandar and Knauss, 1984; Strassburger and Senf, 1995). A propagating crack is accompanied by a relaxation zone whose size is proportional to the crack size. Conversely, the so-called 'plastic velocity' (Zel'dovich and Raizer, 2002) $c_{p}$ can be used to describe the growth of the plastic zone surrounding a growing cavity (Hopkins, 1960; Hunter and Crozier, 1968; Carroll and Holt, 1972). It has been shown that the stress level no longer increases in the plastic zone (Trumel et al., 2009). Further, the issue of micro-inertia, which has not been recognized for a long time, is the subject of continued modeling (see e.g. Ortiz and Molinari, 1992; Tong and Ravichandran, 1995; Wang and Jiang, 1997; Molinari and Mercier, 2001; Wu et al., 2003; Roy, 2003). It does not only slow down the growth of individual pores, but it also confines each growing pore within an evolving neighborhood bounded by elastic relaxation waves. Hence, dynamic pore interactions are strongly linked to pore spacing, themselves driven by the nucleation process. The latter thus 
appears as a crucial mechanism. This is even more important when studying pure materials (e.g. tantalum (Roy, 2003)) over a large range of shock levels and durations, which show extreme size distributions in recovered samples, thereby indicating that nucleation is a continuous process taking place up to coalescence.

In both cases (i.e. brittle and ductile fragmentation), it will be assumed that the growth process is accompanied by a stress relaxation zone in which no new inception event will occur. This observation shows that as soon as the first inception event has occurred, new inceptions are only possible outside the so-called obscuration zones. It is worth noting that unloading waves may interact to form additional cracks (Chambart et al., 2011) and possibly fragments as observed in spallation. This phenomenon will not be accounted for at the microscopic level. Similarly, crack branching or coalescence phenomena are not described hereafter.

In the following, the typical size $\ell_{o b s}$ of the obscuration zone $\Omega_{o b s}$ is assumed to depend upon the difference between the current time $t$ and the time to inception $t_{\text {inc }} \leq t$

$$
\ell_{o b s}=\ell_{o b s}\left(t-t_{i n c}\right)
$$

so that the Lebesgue measure of $\Omega_{o b s}$ reads

$$
\mu_{n}\left(\Omega_{o b s}\left(t-t_{i n c}\right)\right)=S\left[\ell_{o b s}\left(t-t_{i n c}\right)\right]^{n},
$$

where $S$ is a shape parameter (e.g. $S=2$ for a $1 \mathrm{D}$ problem (i.e. $n=1$ ), 
$S=\pi$ for a $2 \mathrm{D}$ problem for which the obscuration zone is a disk, $S=4 \pi / 3$ for a spherical obscuration zone).

The change of $\Omega_{o b s}\left(t-t_{i n c}\right)$ with time defines a spatiotemporal domain in which no new inceptions can occur for any event taking place after $t_{\text {inc }}$. Conversely, the horizon for a given location $(\mathbf{x}, t)$ in space and time of an inception site (Cahn, 1996; Denoual et al., 1997) defines the spatiotemporal domain in which no inception should have occurred. Any point that would have led to an inception and that belongs to the horizon will obscure the given site. Consequently, the inception process becomes nonlocal in a spatiotemporal setting in which obscuration zones develop as more and more inceptions occur, which is less and less likely as higher fractions of the considered domain are gradually obscured.

The following general expression of $\mu_{n}\left(\Omega_{\text {obs }}\right)$ is chosen when ramp loadings are considered (Trumel et al., 2009)

$$
\mu_{n}\left(\Omega_{o b s}\left(t-t_{i n c}\right)\right)=S\left[\frac{v_{p}}{\alpha+1}\left(\frac{\dot{\sigma}}{\sigma_{p}}\right)^{\alpha}\left\langle t-t_{i n c}\right\rangle^{\alpha+1}\right]^{n}
$$

This type of expression can be used to model the fragmentation of brittle materials by setting $\alpha$ to $0, v_{p}$ to the crack propagation velocity (here assumed to be proportional to the longitudinal wave speed $c_{0}$ ). For ductile materials, it was shown by micromechanical arguments (Trumel et al., 2009) that the stress-sensitivity exponent $\alpha=1 / 2$ is a good approximation of the growth of the plastic zone, $\sigma_{p}$ the cavitation stress and $v_{p}$ the plastic velocity (Forrestal and Luk, 1988). 


\subsection{Governing Equations}

Up to now, inception and growth phenomena have been studied for isolated sites (i.e. no interactions have been accounted for between propagating sites and new activated sites). The collective behavior of all propagating sites and the inhibition of new sites is addressed. The obscuration zones around each propagating site introduced in the previous section define regions in which no new inception is possible. Any new inception site should therefore not belong to any obscuration zone. The increment of activated site density $\lambda_{a c t}$ is therefore related to the density of potential inception sites $\lambda$ by

$$
\frac{\mathrm{d} \lambda_{a c t}}{\mathrm{~d} t}=\left(1-P_{o b s}\right) \frac{\mathrm{d} \lambda}{\mathrm{d} t}
$$

where $P_{o b s}$ is the obscuration probability, whose expression is obtained from the condition of finding no inception site in the horizon of the considered site, and the underlying Poisson point process (Denoual et al., 1997; Trumel et al., 2009)

$$
P_{o b s}=1-\exp \left[-\int_{0}^{t} \mu_{n}\left(\Omega_{o b s}(t-\tau)\right) \frac{\mathrm{d} \lambda}{\mathrm{d} \tau}(\tau) \mathrm{d} \tau\right] .
$$

Equation (13) shows that the obscuration probability depends on the convolution product of the Lebesgue measure of obscuration domains with the intensity increment of the Poisson point process.

Of all the activated sites, only a fraction is still growing (i.e. its centers are not obscured). The corresponding density $\lambda_{\text {gro }}$ is related to $\lambda_{\text {act }}$ by

$$
\lambda_{\text {gro }}=\left(1-P_{o b s}\right) \lambda_{a c t}
$$


Equations (12-14) are the governing equations for the dynamic fragmentation model. It is worth noting that in the present case, the spatial variations of the intensity are not considered for the sake of simplicity. The interested reader will find the generalization to this case in (Forquin and Hild, 2010).

Last, in the framework of mathematical morphology, this model constitutes an instance of a Boolean islands model (Jeulin and Jeulin, 1981; Serra, 1982). In the context of isothermal diffusive phase transformations, the previous governing equations are central to the so-called Kolmogorov-JohnsonMehl-Avrami (KJMA) kinetic theory of nucleation and growth (Kolmogorov, 1937; Johnson and Mehl, 1939; Avrami, 1941).

\section{Characteristic Parameters}

In the sequel, a stress ramp with constant rate $\dot{\sigma}$ is applied. In that case, closed-form solutions can be derived for brittle and ductile damage (Denoual et al., 1997; Trumel et al., 2009). The solutions are written in terms of dimensionless stress, time and density when using characteristic parameters.

\subsection{Quasi-Static Loading}

Quasi-static loading conditions for which the weakest link hypothesis applies correspond to cases dealing with brittle materials (Weibull, 1939; Freudenthal, 1968). Necking may also be a phenomenon for which the weakest link applies under quasi-static loading conditions. Conversely, multiple necks can be observed in dynamic loading histories (Zhang and Ravi- 
Chandar, 2006; Besnard et al., 2012). In these cases, the inception probability coincides with the failure probability. The mean inception stress and the corresponding standard deviation are then equal to the mean failure stress $\bar{\sigma}_{f}$ and its standard deviation $\overline{\bar{\sigma}}_{f}$ since brittle fracture is controlled by crack initiation.

It is worth noting that $\bar{\sigma}_{f}$ and $\overline{\bar{\sigma}}_{f}$ are proportional to $\sigma_{0}\left(\lambda_{0} \mu_{n}(\Omega) H_{m}\right)^{-1 / m}$ (see Equations (6) and (7)). For this stress level, the mean number $\bar{N}$ of initiation sites in $\Omega$ is equal to unity. This result is important since it allows for the characterization of the single inception event by the corresponding stress level that depends on the considered domain $\Omega$ and the stress heterogeneity (i.e. $H_{m}$ ). Consequently, volume and stress heterogeneity effects are accounted for in the present setting (Weibull, 1952; Hild and Marquis, 1992). This stress will be referred to as characteristic quasi-static stress.

Another way of accounting for volume and stress heterogeneity effects is through the Lebesgue measure of the effective domain (i.e. $\left.\mu_{n}(\Omega) H_{m}\right)$. The failure probability $P_{f}$, which coincides with the inception probability, then becomes

$$
P_{f} \equiv P_{i n c}=1-\exp \left[-\lambda_{0} \mu_{n}(\Omega) H_{m}\left(\frac{\left\langle\sigma_{m}\right\rangle}{\sigma_{0}}\right)^{m}\right]
$$

where $\sigma_{m}$ is the failure stress. 


\subsection{Dynamic Loading}

For dynamic loading conditions, let us use the same condition as before to define characteristic parameters, namely,

$$
\mu_{n}\left(\Omega_{o b s}\left(t_{c}\right)\right) \lambda\left(t_{c}\right)=1
$$

which requires a single inception event to occur in an obscuration domain $\Omega_{\text {obs }}$ for a time increment $t-t_{\text {inc }}$ equal to $t_{c}$. From Equations (5) and (11), the following characteristic dynamic parameters are obtained

$$
\begin{aligned}
& t_{c}=\left(\frac{\sigma_{0}^{m}}{\lambda_{0}}\right)^{\frac{1}{m+n(\alpha+1)}} \quad\left(\frac{(\alpha+1) \sigma_{p}^{\alpha}}{S^{1 / n} v_{p}}\right)^{\frac{n}{m+n(\alpha+1)}} \quad(\dot{\sigma})^{\frac{-(m+n \alpha)}{m+n(\alpha+1)}} \\
& \sigma_{c}=\left(\frac{\sigma_{0}^{m}}{\lambda_{0}}\right)^{\frac{1}{m+n(\alpha+1)}} \quad\left(\frac{(\alpha+1) \sigma_{p}^{\alpha}}{S^{1 / n} v_{p}}\right)^{\frac{n}{m+n(\alpha+1)}} \quad(\dot{\sigma})^{\frac{n}{m+n(\alpha+1)}} \\
& \lambda_{c}=\left(\frac{\sigma_{0}^{m}}{\lambda_{0}}\right)^{\frac{-n(\alpha+1)}{m+n(\alpha+1)}} \quad\left(\frac{(\alpha+1) \sigma_{p}^{\alpha}}{S^{1 / n} v_{p}}\right)^{\frac{m n}{m+n(\alpha+1)}} \quad(\dot{\sigma})^{\frac{m n}{m+n(\alpha+1)}} \\
& \underbrace{}_{\text {inception }} \underbrace{}_{\text {growth }} \underbrace{}_{\text {loading }}
\end{aligned}
$$

which combine parameters related to inception, growth and loading history (i.e. $\sigma=\dot{\sigma} t$ ). The characteristic dynamic parameters have stress rate dependencies that differ. The characteristic dynamic time $t_{c}$ is inversely proportional to stress rate for high Weibull moduli. In that case, the fragmentation process is completely controlled by multiple inceptions. The corresponding characteristic dynamic stress $\sigma_{c}$ is virtually stress-rate independent as in quasi-static loading. The characteristic dynamic density $\lambda_{c}$ is proportional to the stress rate raised to the power $n$ and inversely proportional to the propagation velocity $v_{p}$ raised to the same power, thereby indicating the competition between stress relaxation described by $v_{p}$ and stress increase 
characterized by $\dot{\sigma}$. Last, the characteristic dynamic measure of $\Omega_{o b s}\left(t_{c}\right)$ is inversely proportional to $\lambda_{c}=\lambda\left(t_{c}\right)$, see Equation (16).

For any value of the Weibull modulus, it is concluded that the characteristic dynamic time decreases as the stress rate increases (with power-law dependence). Conversely, the characteristic dynamic stress and density increase with the stress rate, thereby leading to higher stress levels and activated site densities. This qualitative trends are in agreement with experimental observations concerning brittle materials (Brara et al., 2001; Forquin and Hild, 2010) and ductile materials (Romanchenko and Stepanov, 1980; Meyers and Aimone, 1983; Kanel et al., 1997; Thomason, 1999; Czarnota et al., 2006).

The obscuration probability can be expressed in terms of the dimensionless time $t / t_{c}$ or equivalently the dimensionless stress $\sigma / \sigma_{c}$

$$
P_{o b s}=1-\exp \left[-B(m, n(\alpha+1))\left(\frac{t}{t_{c}}\right)^{m+n(\alpha+1)}\right],
$$

with $B(a, b)=\Gamma(a+1) \Gamma(b+1) / \Gamma(a+b+1)$, and the dimensionless activated site density

$$
\begin{aligned}
\frac{\lambda_{a c t}}{\lambda_{c}} & =\frac{m B(m, n(\alpha+1))^{\frac{-m}{m+n(\alpha+1)}}}{m+n(\alpha+1)+1} \\
& \times \gamma\left[\frac{m}{m+n(\alpha+1)+1} ; B(m, n(\alpha+1))\left(\frac{t}{t_{c}}\right)^{m+n(\alpha+1)}\right],
\end{aligned}
$$

where $\gamma(a ; x)=\int_{0}^{x} \xi^{a-1} \exp (-\xi) \mathrm{d} \xi$ is the incomplete gamma function such that $\gamma(a ; x \rightarrow+\infty)=\Gamma(a)$.

The obscuration probability $P_{o b s}$ can be used to define a damage variable in the framework of continuum damage mechanics (Lemaitre, 1992). Under 
dynamic loading conditions, there is a gradual growth due to the combination of multiple inceptions and simultaneous growth of part of the activated sites. By averaging over a representative zone (e.g. one finite element), $P_{o b s}$ is assumed to be equal to the damage variable $D$, which measures the volume fraction of damaged material (i.e. the union of all obscuration zones in the considered volume). The growth law of the damage variable is given by

$$
D \equiv P_{o b s}=1-\exp \left[-B(m, n(\alpha+1))\left(\frac{\sigma}{\sigma_{c}}\right)^{m+n(\alpha+1)}\right]
$$

where $\sigma$ corresponds to the microscopic stress (i.e. the stress in the undamaged part of the volume element). Consequently, the macroscopic stress $\Sigma$ is related to the microscopic stress by (Denoual et al., 1997; Trumel et al., 2009)

$$
\Sigma=\sigma(1-D)
$$

so that the ultimate tensile strength (UTS) $\Sigma_{U T S}$ reads

$$
\frac{\Sigma_{U T S}}{\sigma_{c}}=[(m+n(\alpha+1)) B(m, n(\alpha+1)) e]^{\frac{-1}{m+n(\alpha+1)}},
$$

the time to reach the UTS, which is usually referred to as the critical time, is given by

$$
\frac{t_{U T S}}{t_{c}}=[(m+n(\alpha+1)) B(m, n(\alpha+1))]^{\frac{-1}{m+n(\alpha+1)}}
$$

and the corresponding damage level

$$
D_{U T S}=1-\exp \left(-\frac{1}{m+n(\alpha+1)}\right)
$$


It is worth noting that the damage model derived in this section incorporates the fragmentation analysis, namely, the damage variable $D$ coincides with the obscuration probability that can be used to compute the density of activated sites (by integrating Equation (12)) and the density of growing sites (by using Equation (14)).

All these results show that once the sought quantities have been made dimensionless (i.e. using their characteristic counterparts), the only parameters that influence the results are the Weibull modulus $m$ characterizing the scatter of inception events, the space dimension $n$, and the power $\alpha$, which is equal to 0 for brittle materials and greater than 0 for ductile materials (Trumel et al., 2009).

\section{Applications}

Various examples will illustrate some of the possible uses of the characteristic parameters introduced above. The first two analyses are based on Monte Carlo simulations in 1D and 3D cases representative of the behavior of brittle materials. Issues related to the choice of the mesh size when using such fragmentation models is then addressed. Last, spallation experiments on tantalum are analyzed.

\subsection{Ring Expansion}

Since the pioneering work of Mott (1947), the ring expansion problem has been one of the basic analyses to discuss fragmentation issues, mostly 
for ductile materials (Rajendran and Fyfe, 1982; Johnson, 1983; Grady and Benson, 1983; Grady and Kipp, 1985; Gourdin, 1989; Altynova et al., 1996; Grady, 2006), but also for brittle materials (Zhou et al., 2005; Grady, 2006, 2010). The fact that it is related to one dimensional analyses makes many calculations easier.

In the following, Monte Carlo simulations are performed with a ring of circumference $\lambda_{c} L \gg 1$ discretized with $N_{e}$ elements of equal length $\lambda_{c} \delta=\lambda_{c} L / N_{e} \ll 1$. These simulations closely follow the simplifying hypothesis consisting of neglecting fragmentations induced by interacting unloading waves in obscuration zones. Finite element simulations are a (much more complex) alternative in which the relevance of that hypothesis can be assessed (Chambart et al., 2011). With the chosen parameters $\left(\lambda_{c} L=100\right.$, $\left.\lambda_{c} \delta=10^{-3}\right)$, it was checked that the distribution of breaks for a Poisson point process follows very closely the asymptotic exponential form valid for an infinite line (Lineau, 1936; Grady, 1990). Figure 1 shows the change of the activated site density as a function of time when normalized by their respective parameters when $m=10$, and $\alpha=0$. The Monte Carlo simulations are in good agreement with the results of Equation (19).

The probability density function $f$ of fragment length $\ell$ at the end of the fragmentation process is approximated by Lineau's law

$$
f(\ell) \approx \lambda_{l} \exp \left(-\lambda_{l} \ell\right)
$$


or its dimensionless equivalent shown in Figure 2

$$
\frac{1}{\lambda_{c}} f(\tilde{\ell}) \approx \tilde{\lambda}_{l} \exp \left(-\tilde{\lambda}_{l} \tilde{\ell}\right)
$$

with $\tilde{\ell}=\lambda_{c} \ell$, and $\tilde{\lambda}_{l}=\lambda_{l} / \lambda_{c}\left(\lambda_{l}\right.$ is the parameter of Lineau's law). The best fit of the numerical results obtained by leaving $\lambda_{l}$ free is compared to the case where $\lambda_{l}=\lambda_{\text {act }}(+\infty)$ in Figure 2. The latter condition corresponds to a good approximation of the numerical results.

\subsection{Single and Multiple Fragmentations}

The present example is devoted to the analysis of the transition between single and multiple fragmentation regimes in uniaxial tension (i.e. $H_{m}=1$ ) of a brittle material (i.e. $\alpha=0$ ). Depending on the stress rate, two different solutions will be found. When the stress rate is low, it is expected that single fragmentation occurs, which is controlled by the first inception. Conversely, for very high stress rates, the first propagating crack has not necessarily traversed the whole domain before other cracks are initiated. In that case, multiple fragmentations are predicted. Therefore, there exists a transition between the two fragmentation regimes when (Denoual and Hild, 2000)

$$
\bar{\sigma}_{f}(V)=\Sigma_{U T S}(\dot{\sigma})
$$

since $\bar{\sigma}_{f}$ depends upon the volume of the considered domain (i.e. $n=3$ ), and $\Sigma_{U T S}$ depends on the stress rate $\dot{\sigma}$ via $\sigma_{c}$. This condition can be rewritten as

$$
\left\{\begin{array}{cl}
\dot{\sigma} \leq \dot{\sigma}_{t} & \text { single fragmentation, quasi-static solution }(6) \\
\dot{\sigma}>\dot{\sigma}_{t} & \text { multiple fragmentation, dynamic solution }(22)
\end{array}\right.
$$


with the transition stress rate $\dot{\sigma}_{t}$ expressed as

$$
\dot{\sigma}_{t}=\dot{\sigma}_{c}\left[\Gamma\left(\frac{m+1}{m}\right)\right]^{\frac{m+3}{3}}[(m+3) B(m, 3) e]^{\frac{1}{3}}
$$

where the characteristic stress rate is given by

$$
\dot{\sigma}_{c}=\underbrace{\frac{\sigma_{0}}{\left(\lambda_{0} V\right)^{1 / m}}}_{\text {inception }} \underbrace{\left(\frac{S\left(v_{p}\right)^{3}}{V}\right)^{1 / 3}}_{\text {growth }}
$$

The characteristic stress rate is proportional to the characteristic quasi-static stress and inversely proportional to the characteristic growth time (i.e. the time for volume $V$ to be fully relaxed). The volume $V$ of the considered domain appears in both parameters. The higher $V$, the smaller the characteristic quasi-static stress, the sooner the transition to multiple fragmentation. Therefore, the regime transition does not only depend upon material (Weibull) parameters but also involves the volume $V$ of the considered domain and the applied stress rate $\dot{\sigma}$. The response of a large volume can be considered as 'dynamic' for low stress rates even if the same material follows the weakest link hypothesis for the same loading applied to a smaller volume. There is therefore no intrinsic relationship between material parameters and characteristic scales to describe the fragmentation of brittle materials.

Figure 3 shows the change of the mean UTS normalized by the characteristic dynamic stress $\sigma_{c}$ with the dimensionless stress rate $\dot{\sigma} / \dot{\sigma}_{c}$. The parameters used in the Monte Carlo simulations correspond to those of a $\mathrm{SiC}$ ceramic (i.e. $m=9.6,1 / \lambda_{0}=1.25 \mathrm{~mm}^{3}, \sigma_{0}=380 \mathrm{MPa}$, and $v_{p}=4300 \mathrm{~m} / \mathrm{s}$, 
see (Denoual and Hild, 2000)). For the sake of simplicity, the considered domain has a volume $V$ equal to $1 / \lambda_{0}$. The two lines represent the analytical quasi-static and dynamic solutions (Equations (6) and (22)) while the circles correspond to the mean of 500 Monte Carlo simulations per stress rate. A very good agreement is observed between the simulations and the closed-formed solutions.

In the present case, the transition takes place over one decade of normalized stress rate. When normalized by the characteristic dynamic stress $\sigma_{c}$, the mean UTS is constant in the multiple fragmentation regime as expected from Equation (22). Conversely, the mean UTS is underpredicted in the single fragmentation regime when normalized by $\sigma_{c}$. A damage model based upon the derivations of Section 3.2 does not apply in that regime.

Last, let us note that such transitions have also been observed when studying the ultimate tensile strength of ceramic matrix composites (Curtin, 1994; Hild et al., 1994). In that case, the obscuration mechanism is related to fiber pullout in the vicinity of fiber breaks, itself driven by the interfacial shear strength. The model used to describe the formation of fiber breaks is also based upon a Poisson point process whose intensity is written in terms of Weibull parameters (Gulino and Phoenix, 1991). The characteristic strength and length are related to the Weibull parameters of the fiber, the fiber radius and the interfacial shear strength (Henstenburg and Phoenix, 1989; Curtin, 1991). 


\subsection{Modeling Issues}

The previous results have some consequences in terms of numerical strategies. Being bounded by 0 and 1 , the obscuration probability can be used as a damage variable. Since the damage variable is associated with obscuration domains, it is associated with a nonlocal model because of the convolution product (see Equation (13)). However, contrary to standard propositions (Pijaudier-Cabot and Bazant, 1987; Allix and Deü, 1997), there is no constant characteristic length or characteristic time, but a growing domain associated with the obscuration length $\ell_{o b s}\left(t-t_{i n c}\right)$ and the propagation velocity $v_{p}$

Moreover, in the multiple fragmentation regime, the mean measure of the obscuration zone is given by

$$
\bar{\mu}_{n}\left(\Omega_{o b s}(t)\right)=\frac{1}{\lambda(t)} \int_{0}^{t} \mu_{n}\left(\Omega_{o b s}(t-\tau)\right) \frac{\mathrm{d} \lambda}{\mathrm{d} \tau}(\tau) \mathrm{d} \tau
$$

The latter depends not only on the propagation velocity but also on the intensity of the Poisson point process describing multiple inceptions. Noting that $\bar{\mu}_{n}\left(\Omega_{o b s}(t)\right) \leq \mu_{n}\left(\Omega_{o b s}(t)\right)$, the latter can be used to check the meshrelevance of finite element calculations. During each time step, the fragmentation variables (i.e. damage or obscuration probability, activated and growing site densities) are computed using the incremental form of the governing equations (12-14). When the measure of each element $\ell_{F E}^{n}$ is less than $\mu_{n}\left(\Omega_{o b s}(t)\right)$, neighboring elements share part of their horizons (i.e. a nonlocal implementation should be considered (Brajer et al., 2010)). 
The nonlocal framework can be used to describe mesocrack coalescence induced by growing microcracks, in particular when studying the fragmentation of glass. Consequently, the nonlocal part is related to the growth a mesocrack that is stopped as soon as the propagation conditions are no longer satisfied (Brajer et al., 2010). Prior to mesocrack or porosity coalescence, the obscuration zone is the result of multiple inceptions and growth (see Equation (31)). After mesoscopic coalescence occurs, the interactions are captured by the numerical scheme and it is mainly controlled by the growth rates of mesocrack or mesovoids.

To avoid such a situation, let us calculate the time at which the damage variable has reached a level of, say, 0.9 (or the obscuration probability is equal to $90 \%$ ) for a constant stress rate. The corresponding normalized time $t_{90 \%} / t_{c}$ is less than 2 when $m \geq 1$, see Figure 4 . Consequently, when $\ell_{F E}^{n} \geq \mu_{n}\left(\Omega_{o b s}\left(2 t_{c}\right)\right)$ or $\lambda_{c} \ell_{F E}^{n} \geq 2^{n(\alpha+1)}\left(\right.$ since $\mu_{n}\left(\Omega_{o b s}(t)\right) \propto t^{n(\alpha+1)}$, see Equation (11)) any point within the horizon associated with the center of a given finite element will always belong to the considered element. A local model (Denoual and Hild, 2000) can be used in that case.

Last, the mean number of potential inception sites $\ell_{F E}^{n} \lambda(t)$ may also be used to know whether deterministic or probabilistic approaches apply. For low stress rates, few fragments are generated (i.e. $\ell_{F E}^{n} \lambda(t)$ is of the order of 1). In that case, a discrete and probabilistic description should be selected (Denoual and Hild, 2002). It consists of modifying the intensity $\lambda$ of the Poisson point process and assigning the first inception stress by randomly 
selecting the inception probability. The first inception stress is evaluated according to Equation (15) with $\mu_{n}(\Omega)=\ell_{F E}^{n}$ and $H_{m}=1$ (i.e. the stress state in each finite element is considered uniform). Conversely, when high stress rates are generated, i.e. $\ell_{F E}^{n} \lambda(t)$ becomes significantly greater than 1, many small fragments are created, and a deterministic model can be considered.

All these issues are direct consequences of the results shown in Figure 3. The latter can be seen as a master plot that only depends upon the Weibull modulus $m$, the space dimension $n$, and the stress sensitivity exponent $\alpha$. Different experimental validations have been proposed for various brittle materials (Forquin and Hild, 2010). In particular, spallation tests on concrete have allowed the prediction shown in Figure 3 to be validated by using the Weibull parameters of the material and its crack propagation velocity (Forquin and Erzar, 2010).

\subsection{Tantalum Spallation}

Spallation of tantalum is briefly analyzed. A typical damaged sample is shown in Figure 5. The interested reader will find additional details in (Roy, 2003; Trumel et al., 2009). Three sets of data are available (Figure 6). First, the change of the pore density $\lambda$ with the shock pressure $\sigma$. Second, the critical time $t_{U T S}$ as a function of the stress rate $\dot{\sigma}$, and third, the spall strength $\Sigma_{U T S}$ versus stress rate. By using the Poisson-Weibull framework summarized above and the expressions of the characteristic parameters, it is 
expected that

$$
\lambda \propto \sigma^{m} \quad, \quad t_{U T S} \propto \dot{\sigma}^{-(m+3 \alpha) /(m+3(\alpha+1))} \quad, \quad \Sigma_{U T S} \propto \dot{\sigma}^{3 /(m+3(\alpha+1))}
$$

since $n=3$. Resorting to least squares fit, the Weibull modulus $m$ is found to be equal to 8 , and the stress sensitivity exponent $\alpha$ to 4.5. A very good agreement is obtained when compared to experimental data (Figure 6). It is however worth noting that the value of $\alpha$ departs from micromechanical analyses that suggest $\alpha=1 / 2$ (Trumel et al., 2009). This final observation shows that the experimental information, which is extremely difficult to get for such types of plate impact tests, is crucial if additional validations are to be performed.

\section{Summary}

A unified probabilistic framework has been introduced to model dynamic fragmentation of brittle and ductile materials. It is based upon Poisson point processes whose intensities depend on Weibull parameters. The governing equations account for random inceptions, which may be inhibited by growing cracks or voids. By analyzing ramp loadings, two sets of characteristic parameters are obtained. The first one is related to single fragmentation, and the second one to multiple fragmentation. In both cases, the condition used to derive the characteristic parameters are related to the discrete inception (and growth) event.

By resorting to Monte Carlo simulations, it was possible to validate simple expressions for the fragment distribution in ring expansion, and the change 
of the ultimate tensile strength of brittle materials with the stress rate. This last result has been used to discuss modeling issues when implementing such fragmentation models in finite element codes. In particular, the size of the elements has to be carefully chosen, and the characteristic parameters can be used to propose guidelines in terms of damage models to be chosen. In particular, the measure of the horizon and its change with time is the key quantity to choose between local and nonlocal, deterministic or probabilistic descriptions of damage models.

Last, experimental data obtained in plate impact tests on high purity tantalum have been used to identify two exponents that appear in the characteristic dynamic parameters when applied to the analysis of ductile spallation. It has been shown that the power-law dependencies with respect to stress and stress rate predicted with the introduced characteristic parameters are in good agreement with experimental observations.

It is worth noting that this type of scaling also applies to quasi-static loading conditions when studying the gradual degradation of composite materials (Henstenburg and Phoenix, 1989; Curtin, 1991; Neumeister, 1993; Hild et al., 1994; Hui et al., 1995), of rocks when analyzing $\mathrm{CO}_{2}$ sequestration in deep reservoirs (Guy et al., 2012), or thermal striping in stainless steels (Malésys et al., 2006, 2009). In all these cases, stable crack networks are formed and then grow with the applied stress, time, or number of cycles. 


\section{Acknowledgments}

The developments presented herein are the result of numerous and fruitful discussions with Drs. Xavier Brajer, Charles Cottenot, Christophe Denoual, Pascal Forquin, Sébastien Grange, René Gy, Yves-Patrick Pellegrini, Laurent Rota, Stéphane Roux, Gilles Roy, Hervé Trumel and Mr. Stéphane Menccaci. Funding from Centre National de la Recherche Scientifique, Délégation Générale de l'Armement, Nitrochimie, and Saint-Gobain is also gratefully acknowledged. Last, this paper is dedicated to the 65th anniversary of Prof. A. Molinari. Happy birthday Alain! 


\section{References}

Allix, O., Deü, J., 1997. Delayed-damage modeling for fracture prediction of laminated composites under dynamic loading. Eng. Trans. 45, 29-46.

Altynova, M., Hu, X., Daehn, S., 1996. Increased ductility in high velocity electromagnetic ring expansion. Metall. Mat. Trans. 27A, 1837-1843.

Avrami, M., 1941. Kinetics of phase change. iii. granulation, phase change, and microstructure. J. Chem. Phys. 9, 177-184.

Bertin-Mourot, T., Denoual, C., Dehors, G., Louvigné, P., Thomas, T., 1997. High speed photography of moiré fringes - application to ceramics under impact. J. Physique IV Coll. C3, 311-316.

Besnard, G., Hild, F., Lagrange, J., Martinuzzi, P., Roux, S., 2012. Analysis of necking in high speed experiments by stereocorrelation. Int. J. Impact Eng. 49, 179-191.

Brajer, X., Hild, F., Roux, S., 2010. On the dynamic fragmentation of glass: A meso-damage model. Int. J. Fract. 163, 121-131.

Brara, A., Camborde, F., Klepaczko, J., Mariotti, C., 2001. Experimental and numerical study of concrete at high strain rates in tension. Mech. Mat. $33,33-45$.

Cagnoux, J., 1985. Déformation et ruine d'un verre pyrex soumis à un choc 
intense : étude expérimentale et modélisation du comportement. Thèse d'etat.

Cahn, J., 1996. The time-cone method for nucleation and growth kinetics on a finite domain, in: MRS Symposium on Thermodynamics and Kinetics of Phase Transformations, Mat. Res. Soc., Pittsburgh, PA (USA). pp. 425438.

Carroll, M., Holt, A., 1972. Static and dynamic pore collapse relations for ductile porous materials. J. Appl. Phys. 43, 1626-1636.

Chambart, M., Levy, S., Molinari, J., 2011. How the obscuration-zone hypothesis affects fragmentation: Illustration with the cohesive-element method. Int. J. Fract. 171, 125-137.

Curran, D., Seaman, L., Cooper, T., Shockey, D., 1993. Micromechanical model for comminution and geranular flow of brittle material under high strain rate. Int. J. Impact Eng. 13, 53-83.

Curtin, W., 1991. Exact theory of fiber fragmentation in single-filament composite. J. Mater. Sci. 26, 5239-5253.

Curtin, W., 1994. Strength versus gauge length in ceramic-matrix composites. J. Am. Ceram. Soc. 77, 1072-1074.

Czarnota, C., Mercier, S., Molinari, A., 2006. Modelling of nucleation and 
void growth in dynamic pressure loading, application to spall test on tantalum. Int. J. Fract. 141, 177-194.

Davies, D., 1973. The statistical approach to engineering design in ceramics. Proc. Brit. Ceram. Soc. 22, 429-452.

Denoual, C., Barbier, G., Hild, F., 1997. A probabilistic approach for fragmentation of ceramics under impact loading. C. R. Acad. Sci. Paris 325, 685-691.

Denoual, C., Hild, F., 2000. A damage model for the dynamic fragmentation of brittle solids. Comp. Meth. Appl. Mech. Eng. 183, 247-258.

Denoual, C., Hild, F., 2002. Dynamic fragmentation of brittle solids: A multi-scale model. Eur. J. Mech. A/Solids 21, 105-120.

Forquin, P., Erzar, B., 2010. Dynamic fragmentation process in concrete under impact and spalling tests. International Journal of Fracture 163, $193-215$.

Forquin, P., Hild, F., 2010. A probabilistic damage model of the dynamic fragmentation process in brittle materials. Adv. Appl. Mech. 44, 1-72.

Forrestal, M.J., Luk, V.K., 1988. Dynamic spherical cavity-expansion in a compressible elastic-plastic solid. J. Appl. Mech. 55, 275-279.

Freudenthal, A., 1968. Statistical Approach to Brittle Fracture. Academic Press, New York (USA). volume 2. pp. 591-619. 
Freund, L., 1972. Crack propagation in an elastic solid subjected to general loading - constant rate of extension. J. Mech. Phys. Solids 20, 129-140.

Glennie, E., 1972. The dynamic growth of a void in a plastic material and an application to fracture. J. Mech. Phys. Solids 20, 415-429.

Gourdin, W., 1989. Analysis and assessment of electromagnetic ring expansion as a high-strain rate test. J. Appl. Phys. 65, 411-422.

Grady, D., 1988. The spall strength of condensed matter. J. Mech. Phys. Solids $36,353-384$.

Grady, D., 1990. Particle size statistics in dynamic fragmentation. J. Appl. Phys. 68, 6099-6105.

Grady, D., 2006. Fragmentation of Rings and Shells: The Legacy of N.F. Mott. Springer.

Grady, D., 2010. Length scales and size distributions in dynamic fragmentation. Int. J. Fract. 163, 85-99.

Grady, D., Benson, D., 1983. Fragmentation of metal rings by electromagnetic loading. Exp. Mech. 12, 393-400.

Grady, D., Kipp, M., 1980. Continuum modeling of explosive fracture in oil shale. Int. J. Rock Min. Sci. \& Geomech. Abstr. 17, 147-157.

Grady, D., Kipp, M., 1985. Geometric statistics and dynamic fragmentation. J. Appl. Phys. 58, 1210-1222. 
Gulino, R., Phoenix, S., 1991. Weibull strength statistics for graphite fibres measured from the break progression in a model graphite/glass/epoxy microcomposite. J. Mater. Sci. 26, 3107-3118.

Guy, N., Seyedi, D., Hild, F., 2012. A probabilistic nonlocal model for crack initiation and propagation in heterogeneous brittle materials. Int. J. Num. Meth. Eng. 90, 1053-1072.

Gy, R., Guillemet, C., 1992. Characterization of a mode of rupture of glass

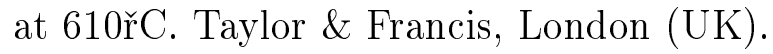

Henstenburg, R., Phoenix, S., 1989. Interfacial shear strength studies using the single-filament-composite test. part ii: A probability model and monte carlo simulations. Polym. Comp. 10, 389-406.

Hild, F., Billardon, R., Marquis, D., 1992. Hétérogénéité des contraintes et rupture des matériaux fragiles. C. R. Acad. Sci. Paris t. 315, 1293-1298.

Hild, F., Brajer, X., Denoual, C., Forquin, P., 2003. On the probabilisticdeterministic transition involved in a fragmentation process of brittle materials. Comput. Struct. 81, 1241-1253.

Hild, F., Domergue, J., Evans, A., Leckie, F., 1994. Tensile and flexural ultimate strength of fiber-reinforced ceramic-matrix composites. Int. J. Solids Struct. 31, 1035-1045. 
Hild, F., Marquis, D., 1992. A statistical approach to the rupture of brittle materials. Eur. J. Mech., A/Solids 11, 753-765.

Hopkins, H., 1960. Dynamic expansion of spherical cavities in metals. NorthHolland, Amsterdam (the Netherlands). volume 1. pp. 84-164.

Hornemann, U., Kalthoff, J., Rothenhäusler, H., Senf, H., Winkler, S., 1984. Experimental Investigation of Wave and Fracture Propagation in Glass - Slabs Loaded by Steel Cylinders at High Impact Velocities. Technical Report EMI report E 4/84, Weil am Rhein (Germany).

Hui, C., Phoenix, S., Ibnabdeljalil, M., Smith, R., 1995. An exact closed form solution for fragmentation of weibull fibers in a single filament composite with applications to fiber-reinforced ceramics. J. Mech. Phys. Solids 43, $1551-1585$.

Hunter, S., Crozier, R., 1968. Similarity solution for the rapid uniform expansion of a spherical cavity in a compressible elastic-plastic solid. Quart. J. Mech. Appl. Math. 21, 467-486.

Jeulin, D., Jeulin, P., 1981. Synthesis of rough surfaces by random morphological functions, in: 3rd European Symposium of Stereology, pp. 239-246.

Johnson, J., 1983. Ductile fracture of rapidly expanding rings. J. Appl. Mech. 50, 593-600. 
Johnson, W., Mehl, R., 1939. Reaction kinetics in processes of nucleation and growth. Trans. Am. Inst. Min. Metall. Eng. 135, 416-458.

Kanel, G., Razorenov, S., Bogatch, A., Utkin, A., Grady, D., 1997. Simulation of spall fracture of aluminum and magnesium over a wide range of load duration and temperature. Int. J. Impact Eng. 20, 467-478.

Kolmogorov, A., 1937. On the statistical theory of metal crystallization. Kluwer Academic Publishers, Dordrecht (the Netherlands). volume II. pp. pp. 188-192 (English translation).

Kutter, H., Fairhurst, C., 1971. On the fracture process in blasting. Int. J. Rock Mech. Min. Sci. 8, 181-202.

Lemaitre, J., 1992. A Course on Damage Mechanics. Springer-Verlag, Berlin (Germany).

Lineau, C., 1936. Random fracture of a brittle solid. J. Franklin Inst. 221, 485-494.

Malésys, N., Seyedi, M., Vincent, L., Hild, F., 2006. On the formation of crack networks in high cycle fatigue. C. R. Mécanique 334, 419-424.

Malésys, N., Vincent, L., Hild, F., 2009. A probabilistic model to predict the formation and propagation of crack networks in thermal fatigue. Int. J. Fat. 31, 565-574. 
Meyers, M., Aimone, C., 1983. Dynamic fracture (spalling) of metals. Progress Mat. Sci. 28, 1-96.

Molinari, A., Mercier, S., 2001. Micromechanical modeling of porous materials under dynamic loading. J. Mech. Phys. Solids 49, 1497-1516.

Mott, N., 1947. Fragmentation of shell cases. Proc. Roy. Soc. London A189, $300-308$.

Neumeister, J., 1993. A constitutive law for continuous fiber reinforced brittle matrix composites with fiber fragmentation and stress recovery. J. Mech. Phys. Solids 41, 1383-1404.

Oakley, D., 1996. An empirical study of the effect of stressed area on the strength of float glass surfaces. J. Non-Cryst. Solids 196, 134-138.

Ortiz, M., Molinari, A., 1992. Effect of strain hardening and rate sensitivity on the dynamic growth of a void in a plastic material. J. Appl. Mech. 59, $48-53$.

Pierce, F., 1926. Tensile tests for cotton yarns, v. the 'weakest link' theorems on the strength of long and of composite specimens. J. Text. Inst. 17, T355-T368.

Pijaudier-Cabot, G., Bazant, Z., 1987. Nonlocal damage theory. ASCE J. Eng. Mech. 113, 1512-1533. 
Rajendran, A., Fyfe, I., 1982. Inertia effects on the ductile failure of thin rings. J. Appl. Mech. 49, 31-36.

Ravi-Chandar, K., Knauss, W.G., 1982. Dynamic crack-tip stresses under stress wave loading. a comparison of theory and experiment. Int. J. Fract. 20, 209-222.

Ravi-Chandar, K., Knauss, W.G., 1984. An experimental investigation into dynamic fracture: Iii, steady-state crack propagation and crack branching. Int. J. Fract. 26, 141-154.

Rinehart, J., 1965. Dynamic fracture strengths of rocks, in: 7th Symp. Rock Mech.

Riou, P., Denoual, C., Cottenot, C., 1998. Visualization of the damage evolution in impacted silicon carbide ceramics. Int. J. Impact Eng. 21, $225-235$.

Romanchenko, V., Stepanov, G., 1980. Dependence of the critical stresses on the loading time parameters during spall in copper, aluminum and steel. J. Appl. Mech. Techn. Phys. 21, 555-561.

Roy, G., 2003. Vers une modélisation approfondie de l'endommagement dynamique ductile. Investigation expérimentale d'une nuance de tantale et développements théoriques. PhD dissertation (in French). 
Serra, J., 1982. Image Analysis and Mathematical Morphology. Academic Press, London (UK).

Shockey, D., Curran, D., Seaman, L., Rosenberg, J., Petersen, C., 1974. Fragmentation of rocks under dynamic loads. Int. J. Rock Mech. Min. Sci. $11,303-317$.

Strassburger, E., Senf, H., 1995. Experimental Investigations of Wave and Fracture Phenomena in Impacted Ceramics and Glasses. Report ARL-CR214. ARL.

Strassburger, E., Senf, H., Rothenhäusler, H., 1994. Fracture propagation during impact in three types of ceramics. J. Physique IV coll. C8, 653-658.

Thomason, P., 1999. Ductile spallation fracture and the mechanics of void growth and coalescence under shock-loading conditions. Acta Mater. 47, 3633-3646.

Tong, W., Ravichandran, G., 1995. Inertial effects on void growth in porous viscoplastic materials. J. Appl. Mech. 62, 633-639.

Trumel, H., Hild, F., Roy, G., Pellegrini, Y., Denoual, C., 2009. On probabilistic aspects in the dynamic degradation of ductile materials. J. Mech. Phys. Solids 57, 1980-1998.

Wang, Z.P., Jiang, Q., 1997. A yield criterion for porous ductile media at high strain-rate. J. Appl. Mech. 64, 503-509. 
Weibull, W., 1939. A Statistical Theory of the Strength of Materials. Technical Report Report 151. Roy. Swed. Inst. Eng. Res.

Weibull, W., 1951. A statistical distribution function of wide applicability. ASME J. Appl. Mech. 18, 293-297.

Weibull, W., 1952. A survey of 'statistical effects' in the field of material failure. Appl. Mech. Rev. 5, 449-451.

Wu, X., Ramesh, K., Wright, T., 2003. The dynamic growth of a single void in a viscoplastic material under transient hydrostatic loading. J. Mech. Phys. Solids 51, 1-26.

Zel'dovich, Y., Raizer, Y., 2002. Physics of Shock Waves and HighTemperature Hydrodynamic Phenomena. Dover, New York, NY (USA).

Zhang, H., Ravi-Chandar, K., 2006. On the dynamics of necking and fragmentation Ü i.real-time and post-mortem observations in al 6061-o. Int J Fract 142, 183-217.

Zhou, F., Molinari, J.F., Ramesh, K., 2005. A cohesive model based fragmentation analysis: Effects of strain rates and initial defects distribution. Int. J. Solids Struct. 42, 5181-5207. 


\section{List of Figures}

1 Dimensionless densities as functions of dimensionless time $t / t_{c}$ for the ring expansion simulation. The dashed line corresponds to the intensity of the Poisson point process, the solid line is the closed-form solution (19) when $m=10$ and $\alpha=0$. The crosses are the results of a Monte Carlo simulation $\left(\lambda_{c} L=100\right.$ and $\left.\lambda_{c} \delta=10^{-3}\right) \ldots \ldots \ldots \ldots \ldots \ldots \ldots$

2 Dimensionless probability density function of the normalized fragment length. The open circles correspond to the result of a Monte Carlo simulation, the dashed line is the best fit by Lineau's law, and the solid line corresponds to Lineau's law whose parameter $\lambda_{l}$ is equal to the mean density of activated sites at saturation $\lambda_{\text {act }}(+\infty) \ldots \ldots \ldots$. . . . . . . 40

3 Mean ultimate tensile strength normalized by $\sigma_{c}$ as a function of the dimensionless stress rate $\dot{\sigma} / \dot{\sigma}_{c}$. The open circles correspond to the results of 500 Monte Carlo simulations for each considered stress rate (Denoual and Hild, 2000). Two fragmentation regimes are observed. For low stress rates, single fragmentation occurs (Equation (6)) while for high stress rates multiple fragmentations are observed (Equation (22)) . . . . 41

4 Dimensionless time $t_{90 \%} / t_{c}$ to reach an obscuration probability equal to $90 \%$ as a function of the Weibull modulus $m$. Two different values of the stress sensitivity exponent $\alpha$ are considered 42 
$5 \quad$ Example of 5-mm thick tantalum sample damaged by symmetric impact at $270 \mathrm{~m} / \mathrm{s}$ by copper flyer plate (the shock wave traveled from top to bottom). Region a: rapidly unloaded, b: biaxially loaded, c: uniaxially loaded. Only the left half of the target is shown. The right edge of the picture corresponds to the symmetry axis $($ Roy, 2003) . . . . . . . . . . . 43

6 Identification of the two exponents $m$ and $\alpha$ for tantalum. (a): Pore density vs. shock pressure. (b): Critical time vs. stress rate. (c): Spall strength vs. stress rate. The open circles are experimental data (Roy, 2003), and the solid lines are results given by Equation (32) when $m=8$ and $\alpha=4.5 \ldots$. . . . 44 


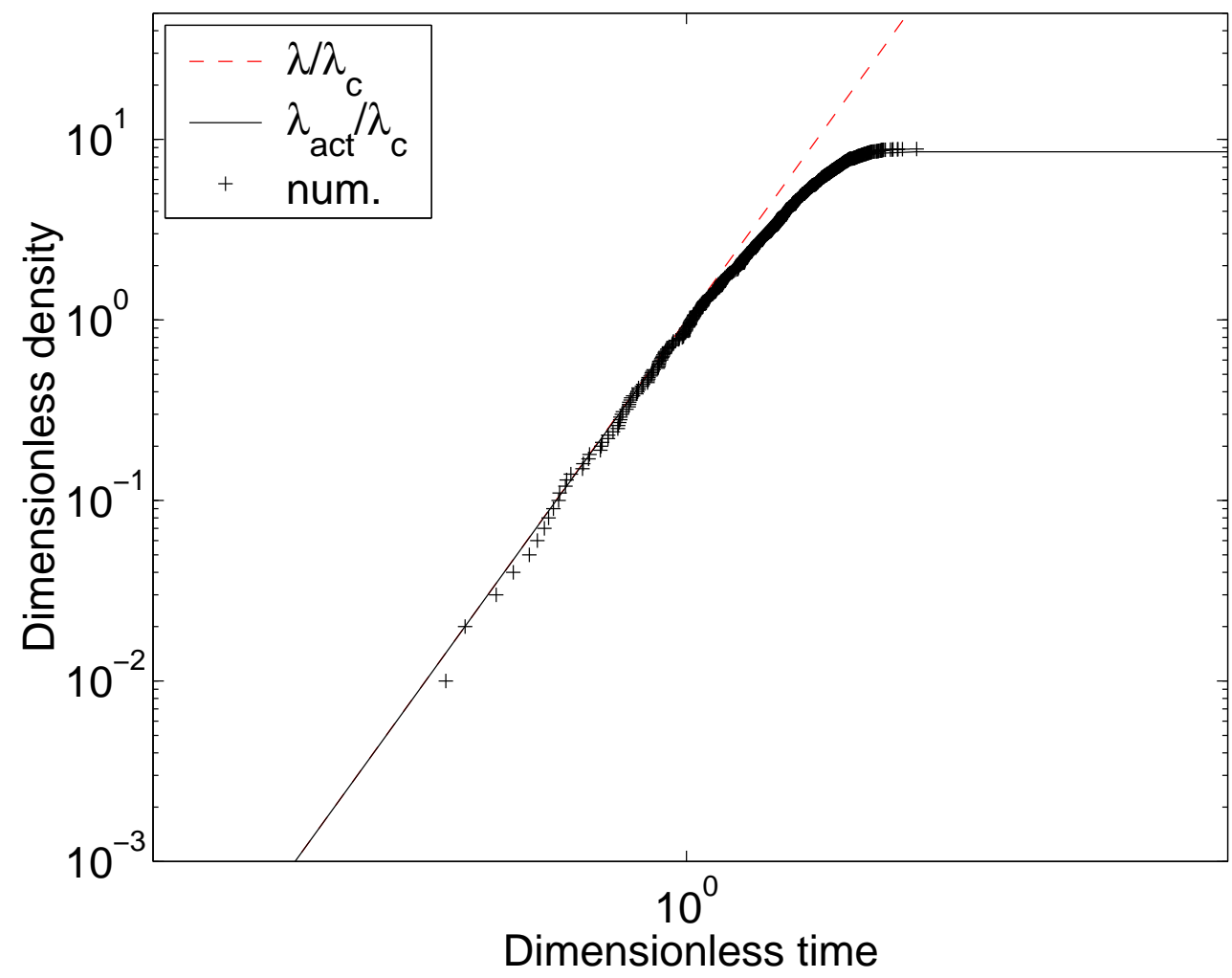

Figure 1: Dimensionless densities as functions of dimensionless time $t / t_{c}$ for the ring expansion simulation. The dashed line corresponds to the intensity of the Poisson point process, the solid line is the closed-form solution (19) when $m=10$ and $\alpha=0$. The crosses are the results of a Monte Carlo simulation $\left(\lambda_{c} L=100\right.$ and $\left.\lambda_{c} \delta=10^{-3}\right)$ 


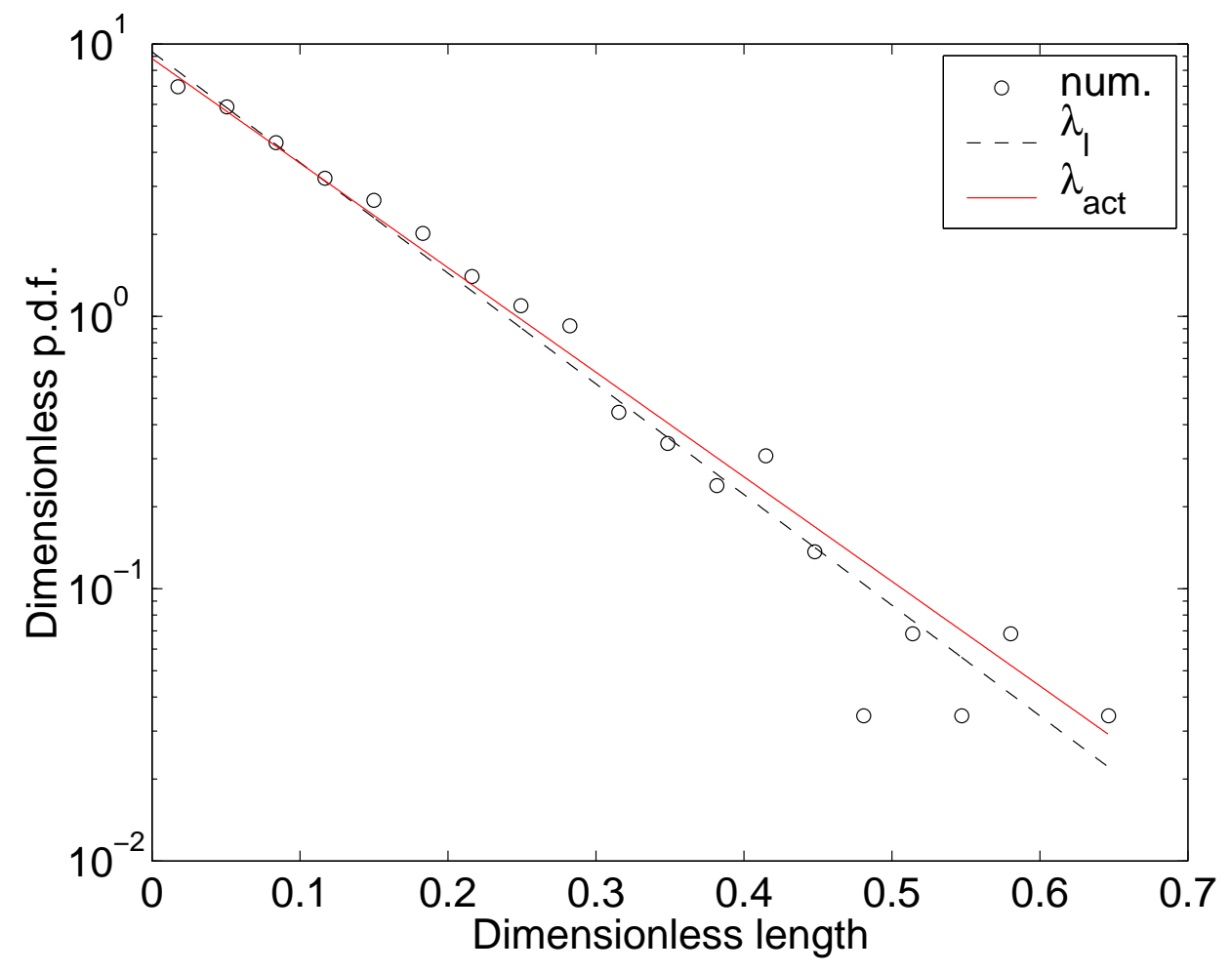

Figure 2: Dimensionless probability density function of the normalized fragment length. The open circles correspond to the result of a Monte Carlo simulation, the dashed line is the best fit by Lineau's law, and the solid line corresponds to Lineau's law whose parameter $\lambda_{l}$ is equal to the mean density of activated sites at saturation $\lambda_{a c t}(+\infty)$ 


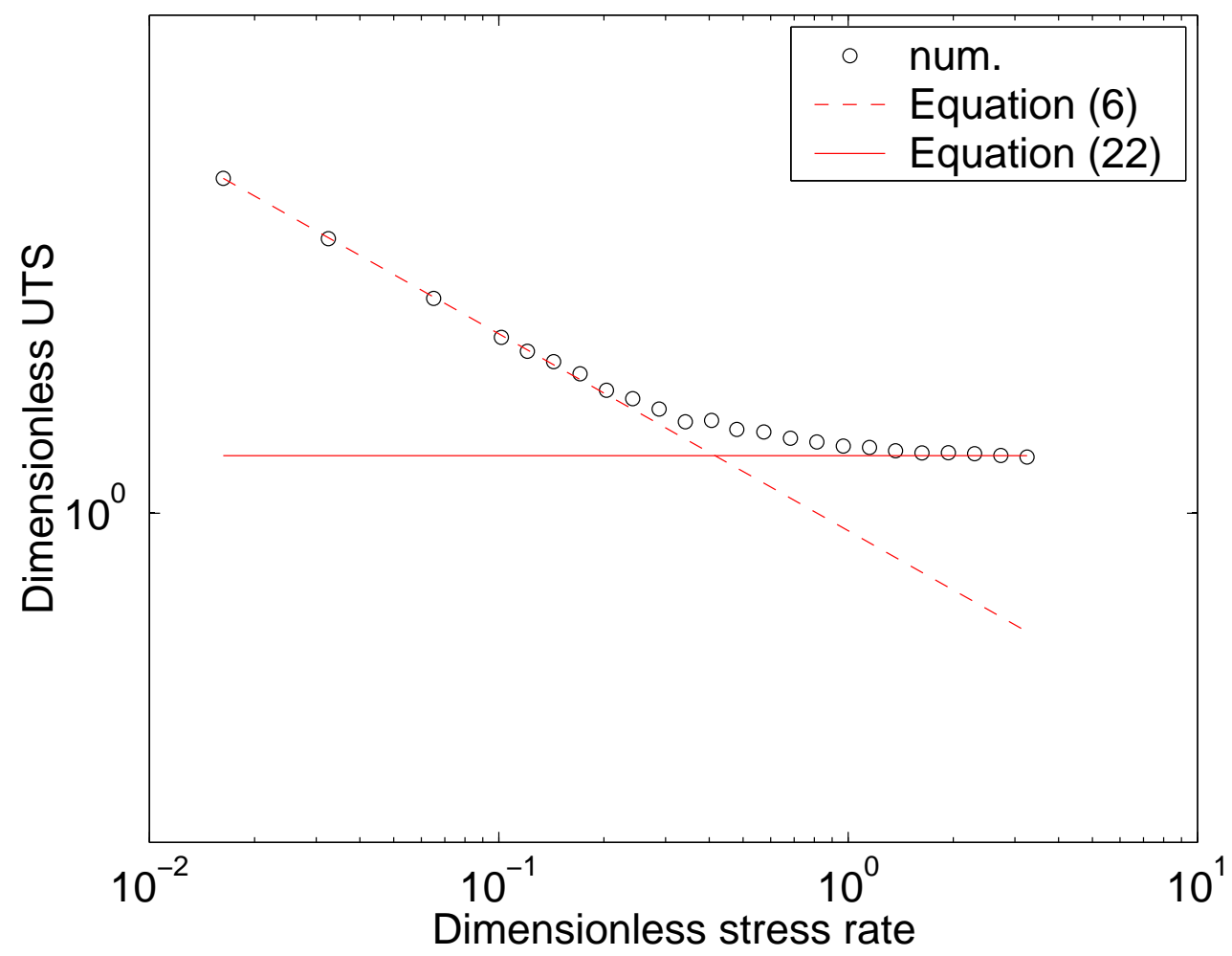

Figure 3: Mean ultimate tensile strength normalized by $\sigma_{c}$ as a function of the dimensionless stress rate $\dot{\sigma} / \dot{\sigma}_{c}$. The open circles correspond to the results of 500 Monte Carlo simulations for each considered stress rate (Denoual and Hild, 2000). Two fragmentation regimes are observed. For low stress rates, single fragmentation occurs (Equation (6)) while for high stress rates multiple fragmentations are observed (Equation (22)) 


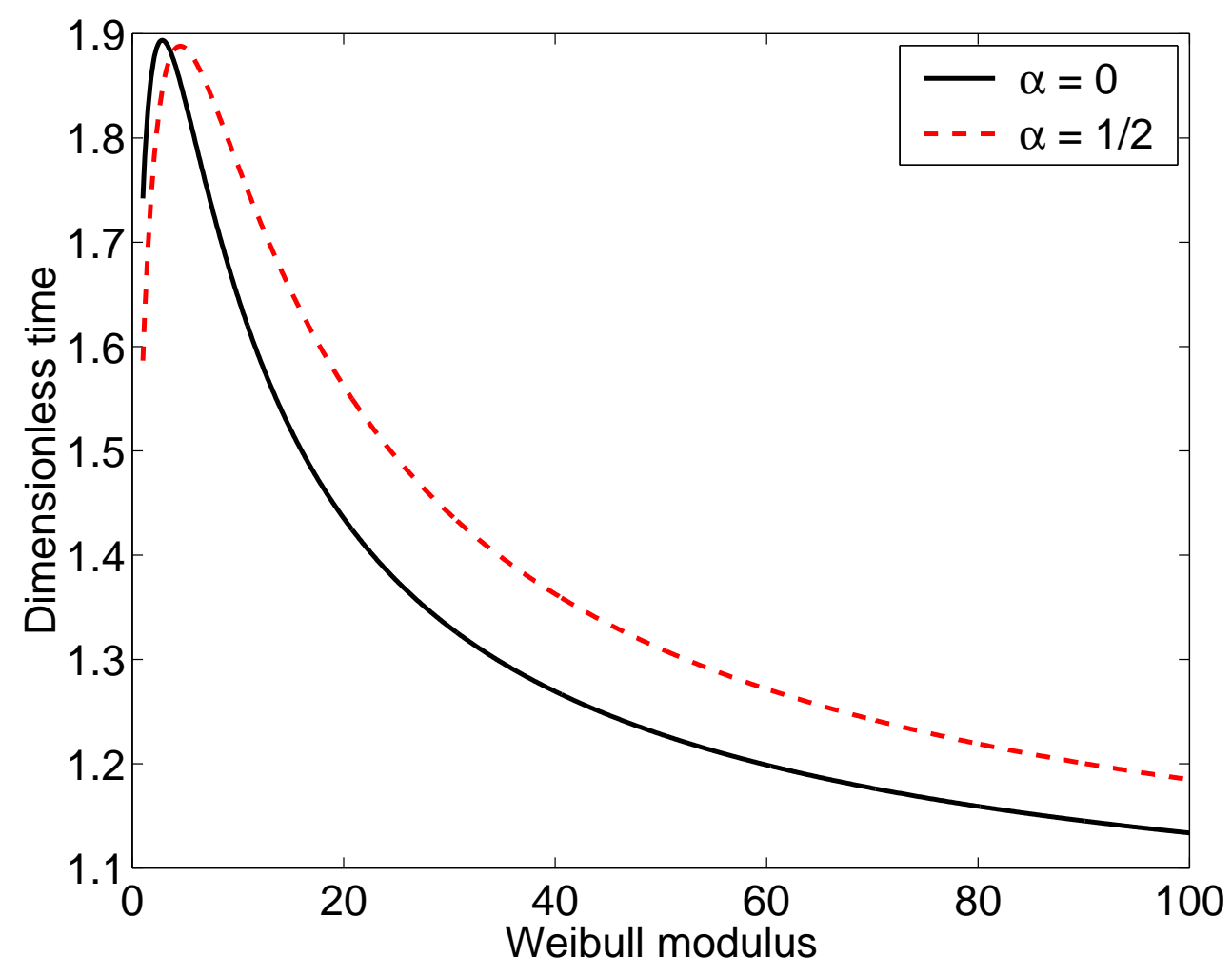

Figure 4: Dimensionless time $t_{90 \%} / t_{c}$ to reach an obscuration probability equal to $90 \%$ as a function of the Weibull modulus $m$. Two different values of the stress sensitivity exponent $\alpha$ are considered 


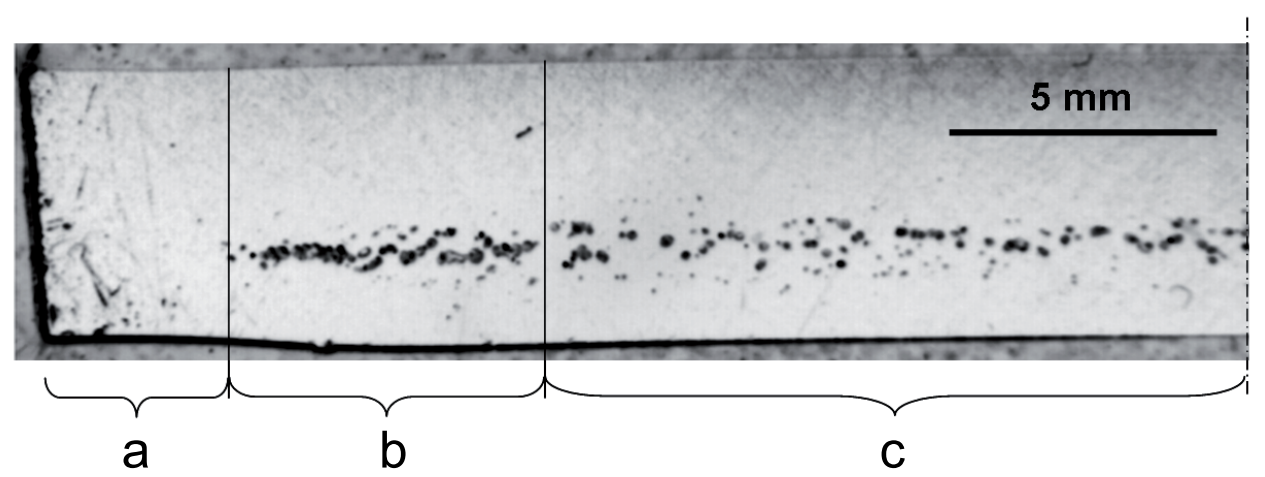

Figure 5: Example of 5-mm thick tantalum sample damaged by symmetric impact at $270 \mathrm{~m} / \mathrm{s}$ by copper flyer plate (the shock wave traveled from top to bottom). Region a: rapidly unloaded, b: biaxially loaded, c: uniaxially loaded. Only the left half of the target is shown. The right edge of the picture corresponds to the symmetry axis (Roy, 2003) 


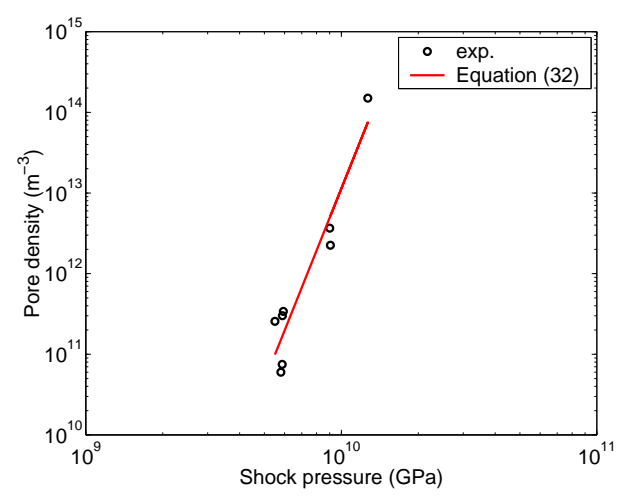

(a)

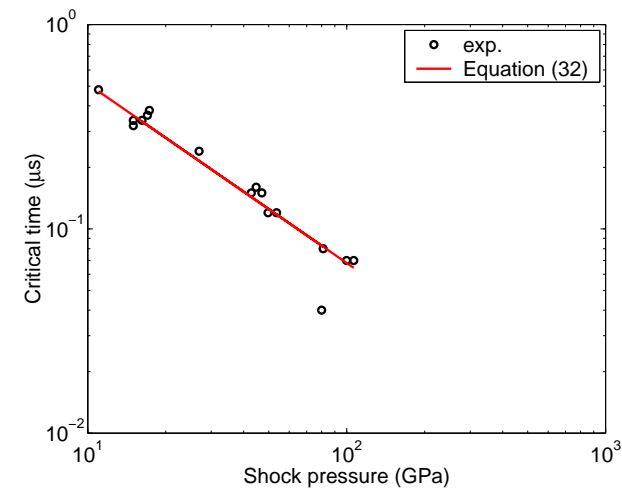

(b)

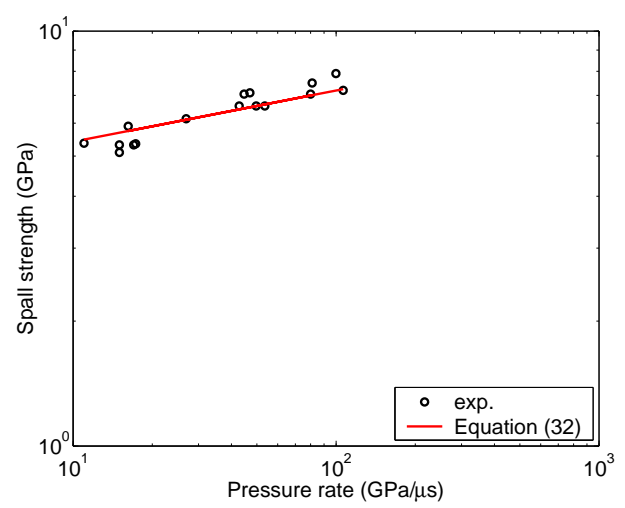

(c)

Figure 6: Identification of the two exponents $m$ and $\alpha$ for tantalum. (a): Pore density vs. shock pressure. (b): Critical time vs. stress rate. (c): Spall strength vs. stress rate. The open circles are experimental data (Roy, 2003), and the solid lines are results given by Equation (32) when $m=8$ and $\alpha=4.5$ 